\title{
Deep Indeterminacy in Physics and Fiction
}

George Darby, Martin Pickup and Jon Robson

\section{Introduction}

\subsection{Indeterminacy}

Indeterminacy in its various forms has been the focus of a great deal of philosophical attention in recent years. Much of this discussion has focused on the status of vague predicates such as 'tall', 'bald', and 'heap'. It is determinately the case that a seven-foot person is tall and that a five-foot person is not tall. However, it seems difficult to pick out any determinate height at which someone becomes tall. How best to account for this phenomenon is, of course, a controversial matter. For example, some (such as Sorensen (2001) and Williamson (2002)) maintain that there is a precise height at which someone becomes tall and such apparent cases of indeterminacy merely reflects our ignorance of this fact. Others maintain that there is some genuine - and not merely epistemic indeterminacy present is such cases and offer various accounts of how best to account for it. Supervaluationists (such as Keefe (2008)), for example, claim that the indeterminacy with respect to vague terms lies in their not having a single definite extension. Rather, each term is associated with a range of possible precise extensions or precisifications such that it is semantically unsettled which is the correct extension. One precisification of 'tall' might allow that anyone over five feet ten inches is tall, whereas another would only allow those over six foot to qualify; but no precisification will take someone who is five foot to be tall, and someone who is seven foot will count as tall on all precisifications. Thus - while someone who is seven foot will be determinately tall and someone who is five foot determinately not so - it will be indeterminate whether someone who stands at five foot eleven inches is tall.

Yet, it is important to stress that putative cases of indeterminacy are not limited to vague predicates of this kind. Philosophers have invoked indeterminacy in discussions of topics as diverse as moral responsibility (Bernstein (forthcoming)), identity over time (Williams (2014)), and the status of the future (Barnes and Cameron (2009)). In this paper, we focus on two areas where discussion of various kinds of indeterminacy has been commonplace: physics and fiction. We propose a new model for understanding indeterminacy across these domains and argue that it has some notable advantages when compared to earlier accounts. Treating physics and fiction cases univocally also indicates an interesting connection between indeterminacy in these two areas. 
In the remainder of this section we briefly survey some issues concerning indeterminacy in our target domains before introducing influential models for addressing them. In $\S 2$ we argue that, as things stand, these models are unable to account for a certain kind of indeterminacy which we label 'deep indeterminacy'. $\$ 3$ introduces our new model for indeterminacy before showing how it can be applied across our two domains. In particular, we highlight ways in which it is able to account for the kinds of deep indeterminacy we introduced in $\S 2$. In $\S 4$ we offer some concluding remarks.

\subsubsection{Metaphysical Indeterminacy}

Metaphysical indeterminacy is indeterminacy that is non-representational. This contrasts it with the vague predicate cases discussed above. Metaphysical indeterminacy is vagueness in the world, not just vagueness in our representation of the world. But the intuitive idea of metaphysical indeterminacy as indeterminacy that is non-representational requires elaboration. One line here is that metaphysical indeterminacy is that indeterminacy that would remain even if the all of the representational indeterminacy were removed - that is, if the language were completely precisified. Questions about what metaphysical indeterminacy is supposed to be intersect of course with the question of whether there really is, or could be, any. A skeptical tradition famously writes off the idea as incoherent, or only coherent enough to be seen to be impossible, or similar.

In response to that skepticism, metaphysicians have recently been constructing explicit models of metaphysical indeterminacy. Examples include Akiba (2004), Barnes and Williams (2011) and Wilson (2013). Here we focus on a particular class of models along the lines of those that Wilson calls "meta-level" accounts (in contrast to her own "object-level" view). The models we are interested in have a form analogous to linguistic indeterminacy as alluded to above: Where language could be more precise, but is not, with something's being indeterminate if true on some precisifications of the language and false on others, so the metaphysical version has it that the world could be more precise, but is not, with something's being indeterminate if true on some precisifications of the world and not on others. We will focus on one particular meta-level model of metaphysical indeterminacy: the one proposed by Barnes and Williams (2011). Barnes and Williams (BW hereafter) use possible worlds to give their account: metaphysical indeterminacy is to be understood by using sets of possible worlds that differ with respect to the truth of some propositions. The members of these sets of possible worlds are those worlds that are candidates for 
being the way the world really is. The propositions they do not agree on are the propositions that are metaphysically indeterminate. The BW model therefore treats metaphysical indeterminacy in much the way that supervaluationists treat representational indeterminacy. The details of the BW approach will be discussed in section 1.1.3. First we introduce fictional indeterminacy.

\subsubsection{Fictional Indeterminacy}

Before we can discuss fictional indeterminacy, we need to briefly consider some more general issues concerning the nature of fictions. In particular, we need to consider the question of what is required for some claim to be true within a certain fiction. It is a commonplace that not everything that is true in a particular fiction is explicitly stated in the fiction itself. Consider, for example, that the majority of fictional characters we encounter are more or less ordinary human beings. They lack the ability to fly under their own power, they have never engaged in exotic practices such as time travel or astral projection, and they breathe oxygen rather than methane or gold dust. Yet it is exceedingly rare for an author to take the time to explicitly highlight any of these features (rather it is the exceptions that tend to warrant particular notice). This much is generally taken to be uncontroversial (though D'Alessandro (forthcoming) questions this orthodoxy) but disputes quickly arise as to precisely what account we should give of something's being true in a given fiction. According to Greg Currie (1990: 80) what is true in a fiction is what 'it is reasonable for the informed reader to infer that the fictional author' of the fiction in question believes. ${ }^{1}$ Derek Matravers (1997: 423) takes it to be a matter of 'what it would be reasonable for the reader to infer (within the game of imagining the text is true)'. Christopher New (1997: 422) claims that it is determined by 'what the author's sentences mean [...] and what they logically or pragmatically imply in accordance with the conventions of fiction making prevailing at the time he composed the fiction'. And Stacie Friend (2011: 187) argues:

that an utterance ' $S$ ', occurring in the context of a discussion of a fiction $F$, is true if and only if F prescribes imagining that $S$. This will be either because ' $S$ ' is to be understood as meaning, or getting across, something like 'According to $\mathrm{F}, S$ ', or because it is to be understood as a continuation of the imaginative engagement authorized by $\mathrm{F}$.

\footnotetext{
${ }^{1}$ For an explanation of the key notion of a 'fictional author' see Currie (1990: 75-80).
} 
Probably the most influential account of truth in fiction, though, is Lewis (1978), according to which whether something is true in a fiction is, loosely speaking, determined by what it true at the nearest worlds where the fiction is told as known fact; the nearest worlds, that is, either to the actual world or to that set of worlds that represents the collective beliefs of the storyteller's community (for ease of exposition we will focus on the former). In the rest of this paper we will primarily focus on a discussion of Lewis's view but a number of the key claims we make may also be applicable (mutatis mutandis) to other accounts of fictional truth. In section 1.1.4 we will outline Lewis's view, and its consequences, in more detail. First, though, we shift focus from fictional truth to fictional indeterminacy.

It is generally accepted that many (perhaps all) fictions are indeterminate in some respects. The most prominent kind of fictional indeterminacy involves a fairly straightforward kind of fictional incompleteness. There are many things about the inhabitants of fictional worlds that just aren't specified. Consider the famous case of Lady Macbeth and her children. It is clear from Lady Macbeth's claim 'I have given suck, and know how tender 'tis to love the babe that milks me' that she has at least one child, but it is almost universally agreed that there is no specific number of children which it would be correct to attribute to her. Indeed, Knights' (1933) intention in raising this question in his famous paper was to poke gentle fun at anyone inclined to think there could be a determinate answer to such inquiries. Similarly, while it is true in the fiction that many characters have full heads of hair it would seem bizarre to believe that there is some fact of the matter about precisely how many hairs each of them has. Indeed, indeterminacy of this kind is so pervasive that some are inclined to maintain that in 'a fictional world it will normally be the case for each character $a$ and some relevantly applicable predicate $\mathrm{F}$ that neither $\mathrm{F} a$ nor $\sim \mathrm{F} a$ is true' (Heintz 1979: 91). However, while indeterminacy of this kind has received the lion's share of attention in the literature, there are a number of other ways in which a more robust fictional indeterminacy, rather than this commonplace kind of incompleteness, might arise.

Most obviously there are fictions that are indeterminate because they feature common-orgarden cases of vagueness; what Sorensen (1991: 66) calls 'vagueness within a story'. For example, we might be told that a character is 175 millimetres tall or that they have exactly $n$ hairs on their head but still judge it to be indeterminate whether they are tall or whether they are bald (in much the same way as we would when given this same information concerning some non-fictional individual).

Likewise, we may encounter a fiction such as Robert Anton Wilson's Schrödinger's Cat 
Trilogy which presents us with various examples of indeterminacy in physics. How best to account for this kind of indeterminacy is, of course, a controversial matter. Someone who inclines towards the account of real world indeterminacy we outline below will, most likely, also take it to be the best explanation for parallel kinds of indeterminacy as they arise within a fiction. ${ }^{2}$ However, such cases hardly present an independent motivation for accepting our view. Such a motivation can, however, be found by investigating a third kind of fictional indeterminacy.

Consider the following questions. Is the governess in James's The Turn of the Screw haunted by supernatural apparitions or merely by symptoms of her own mental instability? Which of the two apparent realities in Smith's 'In the Imagicon' is the real world? Is the eponymous Babadook in the recent film a real monster or merely a representation of Amelia's grief? It seems to many (ourselves included) as if there are no determinate answers to these questions. We will, however, argue below that there is an important difference between these examples and the kind of indeterminacy as incompleteness discussed above. This difference is often overlooked in discussions of fictional truth. ${ }^{3}$ In the Lady Macbeth case it seems entirely incidental to the narrative that there is no determinate fact of the matter concerning the number of her progeny. By contrast, an alternative version of 'In the Imagicon' that revealed in the final sentence which of the two worlds was the real one would, ceteris paribus, be a significantly inferior story. Just as a close parallel to The Turn of the Screw which took the form of an unambiguous ghost story would lack much of what made the original so engaging. The kind of indeterminacy we are focusing on in such works is not merely incidental but, rather, plays an important role in their artistic success.

We will argue below (in section 3.3) that, for someone broadly in sympathy with Lewis's project, the best way to account for indeterminacy of this kind requires treating it as fundamentally different from the kind of indeterminacy as incompleteness that has been the main focus of discussion in the literature. Before doing so, though, we will need to present Lewis's view in truth, and indeterminacy, in fiction in rather more depth (section 1.1.4) as well as showing why we believe it is incapable of properly accounting for indeterminacy of this kind (section 2.2). But first, we return to outline the account of metaphysical indeterminacy that provides our starting point.

\footnotetext{
${ }^{2}$ There may, of course, be some exceptions to this such as philosophical fictions where we are explicitly told that some other account of indeterminacy holds.

3 Though, of course, The Turn of the Screw is itself frequently discussed in such debates (see, e.g., Currie (1990: 66-7), Matravers (1997: 425) and Stecker (1995: 16).
} 


\subsubsection{The Barnes-Williams model for metaphysical indeterminacy?}

We can now spell out in more detail the BW account of metaphysical indeterminacy. According to this influential view "there is the One True actualized world - it is just indeterminate which world this is" (2011, p.131ff). In other words, there really is one actual world, but which one that is is itself indeterminate. Metaphysical indeterminacy is a matter of the indeterminacy of which world is the One True world. Formally, this means that instead of evaluating propositions at a specific (maximal, sharply defined) world, we evaluate them on sets of worlds.

In the BW model the candidate "precisifications of the world" are ersatz possible worlds: It is indeterminate whether $\mathrm{p}$ if some of the ersatz worlds that are candidates for representing actuality are $p$ worlds, and some are $\sim p$ worlds. To be a candidate for representing actuality is to not determinately fail to represent actuality. (Thus the BW model is not reductive in an important sense, but that is not our focus here.)

BW claim that this theory is fully bivalent and that it is committed to the principle of excluded middle. It is committed to the former because there is One True world (even though it is indeterminate which candidate it is) and for every possible world that is a candidate, for any proposition $\mathrm{p}$, either $\mathrm{p}$ is true in that world or $\mathrm{p}$ is false in that world. And the theory is committed to the principle of excluded middle because for any proposition $p,(p \vee \sim p)$ is definitely true.

The supervaluational character of the models, and the connection to possible worlds, make indeterminacy analogous to modality: Typically it will not be definite that $\mathrm{p}$ and not definite that $\sim p$; thus indeterminacy is to definiteness as contingency is to necessity. And just as a disjunction will often be necessary while its disjuncts are contingent, so "the university is in the city centre" and "the university is in the suburbs" may both be indeterminate while "the university is either in the city centre or in the suburbs" is determinately true.

The comparison with possible worlds is suggestive for our later proposal. To foreshadow our argument, we will claim that in order to account for deep indeterminacy we need a treatment analogous to that of modal logic using less-than-maximal possibilities instead of the more familiar possible worlds.

\subsubsection{A Lewisian approach to indeterminacy in fiction}


Having given some detail on the BW model for metaphysical indeterminacy, we can likewise explain more fully the Lewisian approach to fictional indeterminacy. Lewis proposes (1978: 42) the following influential account of fictional truth:

A sentence of the form "In the fiction $f, \phi$ " is non-vacuously true iff some world where $\mathrm{f}$ is told as known fact and $\phi$ is true differs less from our actual world, on balance, than does any world where $\mathrm{f}$ is told as known fact and $\phi$ is not true. It is vacuously true iff there are no possible worlds where $\mathrm{f}$ is told as known fact.

This account is relatively simple but has a great deal of explanatory power. In particular, it allows us to easily explain why many things are true within a particular fiction even when not explicitly presented as being so in the fiction itself. It is true, for example, that the characters who inhabit most of our everyday fictions are ordinary human beings because the nearest worlds where those stories are told as known fact are all ones where the individuals involved are human beings rather than, say, shockingly advanced robots.

Lewis's account of fictional truth also seems very well placed to deal with certain kinds of fictional indeterminacy. As part of his analysis of truth in fiction Lewis (ibid.) raises questions such as 'Is the world of Sherlock Holmes a world where Holmes has an even or an odd number of hairs on his head at the moment when he first meets Watson? What is Inspector Lestrade's blood type?' and concludes that it would be absurd to suppose that such questions have answers. This is not, however, because there is any world in which the Holmes stories are told as known fact where these questions have no answers. Rather, such questions lack a correct answer because truth in a fiction is determined not by what is true in some single possible world but by what is true in a set of worlds. The 'worlds of Sherlock Holmes are plural, and the questions have different answers at different ones' (ibid). Those things that are true in every one of these worlds - that Holmes is a detective, that he is a human being, that he has never met Jeff Bridges and so forth - are true in the fiction. Those things that are false in every one of these worlds - that Holmes is a silicon based lifeform, that he owns a mobile phone, that he was once married to Carly Simon and so on - are false in the fiction. However, what is true in some of these worlds and false in others is neither true nor false in the fiction and any answer to the silly questions Lewis lists would fall into this category. ${ }^{4}$ And, of course, what applies in the Holmes stories applies to the other cases of indeterminacy as

\footnotetext{
${ }^{4}$ Well, not quite any answer. It is, for example, determinately true that Lestrade's blood type is one of those possessed by some relatively healthy human beings in the actual world.
} 
incompleteness we have listed above. The claim that Lady Macbeth has exactly three children is true in some worlds where Macbeth is told as known fact but false in others. As such, it is neither true in the fiction that she has precisely three children nor true in the fiction that she does not.

Further, the Lewisian seems to have ample resources available to deal with the phenomenon of vagueness within a story. Whatever account we give of vagueness in the actual world this account will, presumably, also be available to explain cases of vagueness in the nearest world where the fiction in question is told as known fact. We will, however, go on to argue (in section 2.2 below) that the Lewisian account is unable to account for the third kind of fictional indeterminacy we have highlighted above.

\section{The challenges of deep indeterminacy}

Although we have sympathy with both the BW model of metaphysical indeterminacy and with the Lewisian model of fictional indeterminacy, they both suffer from a structurally similar problem. In both cases, the models are unable to adequately capture the full range of cases that fall under the relevant notion of indeterminacy. Further, they fail to do so in the same way.

There are versions of both metaphysical and fictional indeterminacy that are particularly resistant to domestication. This is what we call 'deep' indeterminacy. A form of indeterminacy is deep when it comes from the nature of the domain under discussion. Or, to put it differently, deep indeterminacy is the sort of indeterminacy that is built into the theory, rather than being a corollary of that theory. To make this clearer, consider the two cases we have before us. Deep metaphysical indeterminacy is non-representational indeterminacy that arises from the theoretical structure of accounts of the world. The particular instance we will discuss shortly relates to certain interpretations of quantum mechanics. On these interpretations, it is part of the nature of the quantum theory that worldly indeterminacy occurs. This is cashed out by mathematical constraints on possibility. Deep fictional indeterminacy is indeterminacy in fiction where the structure of the fiction itself is the source of the indeterminacy. It is, in a sense we will explicate further below, part of the nature of the fiction that there is indeterminacy. This can be cashed out by appeal to identity 
constraints on works of fiction: to be that very story is to contain indeterminacy of this sort.

Deep indeterminacy has the following feature: it is hard to supervaluate away. This is because constructing alternative candidates over which to supervaluate is complicated by the constraint that these candidates are both determinate and genuine candidates. How can fully determinate and complete accounts of the world be real candidates for being a deeply indeterminate world? In both the metaphysical and the fictional cases, it isn't possible to capture the indeterminacy in question within the models discussed.

Our answer is to adjust these models to give up on the completeness of the candidates: rather than dealing with possible worlds we deal with smaller possibilities. We will also require controversial claims about the relationship between truths of propositions in different, mereologically related possibilities. But first, we will explain why there is reason to believe in such deep indeterminacy (both metaphysical and fictional) and spell out the inadequacy of sets of complete, determinate candidates as a means of accurately representing this.

\subsection{Deep Metaphysical Indeterminacy}

The possibility of deep indeterminacy, and the inadequacy of the BW account in capturing it, becomes apparent when we consider the way in which quantum mechanics is supposed to provide a motivating example for the metaphysician's project of theorizing about metaphysical indeterminacy.

If quantum mechanics is to serve as an example of metaphysical indeterminacy, the obvious idea is to interpret Heisenberg's Uncertainty Principle as involving indeterminacy: If something has a definite position, then it lacks a definite momentum; its momentum is indeterminate. Likewise perhaps it is indeterminate whether Schrodinger's cat is alive before the box is opened. So we have indeterminacy, and, importantly, its treatment has the same kind of "supervaluational" structure as linguistic indeterminacy: In the appropriate state it is definite that the cat is alive or the cat is dead but not definite that the cat is alive or definite that the cat is dead; it is indeterminate whether the cat is alive. unusual, but requires very particular interpretative assumptions. We do not go into these details 
here - we propose to take for granted whatever assumptions one needs to get an example of metaphysical indeterminacy; we note just that those assumptions are controversial, but also commonly made.s[ipiThere are certainly interpretations of quantum mechanics that, prima facie, involve genuine indeterminacy (although no concrete metaphysical account of that indeterminacy is part of the interpretation). The earlier versions of the GRW theory are likely candidates. One might worry, however, that in more recent interpretations indeterminacy disappears along with the measurement problem. For example, in the modern Everett interpretation, the underlying ontology, from which the branches emerge, is perfectly determinate (whether the branches themselves are is another matter, but the underlying ontology is the level at which one would naturally judge the question of whether there is metaphysical indeterminacy). In the modern "flashy" GRW theory, the distribution of flashes in spacetime is also perfectly determinate. If one subscribes to the view that, one way or another, what is fundamental is the wave function evolving in configuration space then yet again the fundamental ontology is perfectly determinate. Perhaps there is a sense in which derivative ontology that does include indeterminacy still falls under what is intended by "metaphysical indeterminacy", but this is much less clear. So one might take the view that, initial appearances notwithstanding, properly interpreted quantum mechanics does not involve any metaphysical indeterminacy either.

Again, then, we register caution but proceed with the consensus (of Wilson (2013), Williams (2008) and Bokulich (2014), for example) that there is at least motivation from physics for seeking an account of metaphysical indeterminacy. An important point here is that there is good reason for thinking that indeterminacy in quantum mechanics is reliably worldly, not merely representational. The basic reason for thinking that the theory involves indeterminacy is because it does not give precise values for all observables (for example, no value for position in many states, and definitely not both a value for position and a value for momentum in any state at all). The reason for thinking that quantum mechanics involves metaphysical indeterminacy is that it does not even make mathematical sense to give precise values for all observables. This is the gist of the various results that culminate in the Kochen-Specker theorem and its subsequent refinements. is substantial reason for thinking that there is metaphysical indeterminacy involved.s matters in the present context is that this very reason for thinking that quantum mechanics involves metaphysical indeterminacy presents a problem for many of the models whose authors invoke it as motivation. With Skow, we present the challenge as an argument against the BW model, but suspect that it may also cause trouble for other models. The problem is simply that BW model 
indeterminacy using ersatz possible worlds: to be indeterminate is to hold in some but not all of the ersatz worlds that are candidates for representing actuality. Worlds by their nature are maximal in the sense of settling everything; thus in every world every observable gets some value. But the essence of the Kochen-Specker result is that it is impossible for every observable to have a value at once. Thus this kind of "deep" indeterminacy cannot be modelled by the BW framework.

There are a number of ways in which one might respond to this argument. For a start, if one begins with the vector space formalism and tries to read it as involving metaphysical indeterminacy, there are all of the interpretive assumptions that go into the particular interpretation of the formalism required (the eigenstate-eigenvalue link and so on). These assumptions then have to be further strengthened (for example by assuming that they have to hold at all of BW's ersatz worlds) in order to generate the problem for the models of indeterminacy. If on the other hand one thinks about things from the point of view of the specific proposals for solving the measurement problem, then it is not clear that they involve indeterminacy at all, a fortiori not deep indeterminacy. (This response is dialectically unattractive for the advocates of metaphysical indeterminacy, of course, since it removes not just the obstacle to its modelling but also its motivation.)

With this in mind, we propose to treat the objection as a plausibility argument, irrespective of its cogency from the point of view of the philosophy of physics. That is, we will not follow Skow in claiming that the Kochen-Specker result shows that deep indeterminacy is clearly possible, exactly, but just that it is at least important to explore how theories of metaphysical indeterminacy should handle it. In methodological terms related to the now familiar science-based objections to armchair metaphysics, the point is just to avoid leaving unnecessary hostages to fortune. In terms less influenced by the naturalistic objections, the point might be that even if one is completely unswayed by the scientific point, there is no reason from the armchair, now that it has been pointed out, why deep indeterminacy should be impossible. It sounds, on the surface at least, like it should be possible if any kind of metaphysical indeterminacy is, and so should be accounted for by an acceptable theory.

What we have here, then, is one motivation for exploring whether one can model deep indeterminacy in something like the BW framework.

\subsection{Deep Fictional Indeterminacy}


The second motivation likewise comes from deeper consideration of the kinds of fictional indeterminacy that are possible. We have seen that Lewis's account of fiction can provide a plausible explanation for certain varieties of fictional indeterminacy and, in particular, that he offers an attractive account of the kind of indeterminacy which arises owing to fictional incompleteness. Our third kind of indeterminacy concerning, for example, which of the two worlds in 'In the Imagicon' is real is often treated, when it is discussed at all, as merely a particularly interesting variety of this kind of indeterminacy. The only relevant difference is that the incompleteness is intentional rather than merely accidental. Matravers (1997: 425), for example, propounds something like this view when he claims that 'in The Turn of the Screw, Henry James toys with us by not providing conclusive evidence for choosing one of two worlds' ${ }^{5}$ That is, James deliberately provides insufficient information for us to judge whether The Turn of the Screw is a ghost story just as Conan Doyle happens not to tell us precisely how many hairs Holmes has on his head at that faithful moment.

We think, however, that the indeterminacy in such cases is importantly different from the standard kind discussed above. It is not merely a matter of what the storyteller neglects to specify but, rather, it is essential to the nature and value of the work that no such specification is provided. Of course, there is some controversy with respect to precisely which works exemplify indeterminacy of this kind. There are, for example, those (such as Currie (1991: 182)) who are inclined to regard The Turn of the Screw as definitively a ghost story and others who follow Kenton (1924) in subscribing to a straightforwardly psychoanalytic reading. However, the point remains that indeterminacy of this kind clearly exists in some fictions and it is important for a full account of fiction, and fictional truth, to accommodate such fictive deep indeterminacy. As it stands, however, we believe that Lewis's account is unable to do so.

To see why, let's return to the contrast with the Lady Macbeth case discussed above. There are various worlds where Macbeth is told as known fact in which it is perfectly determinate that Lady Macbeth has precisely three children, others where it is determinate that she has precisely four and so forth. As such, while there may be some things that are indeterminate within the fiction (because they are true in some Macbeth worlds and false in others) each of these individual worlds is perfectly determinate. Or, rather more precisely, if such worlds are indeterminate this will only be so because of features external to the debate over truth in fiction; standard cases of vagueness, indeterminacy in physics, and so forth (when discussing whether fictional worlds are determinate

${ }^{5}$ And Stecker (1994: 201) makes similar remarks. 
below we will, for the most part, bracket such considerations).

In contrast, we maintain that there is no fully determinate possible world where stories such as The Babadook are told as known fact. There are, of course, worlds where certain determinate stories very much like The Babadook are told as known fact. Stories that determinately feature a real monster are told as known fact in some worlds and stories where such supernatural entities are determinately absent are told in others. However, the crucial difference is that none of these are really tellings of The Babadook. Rather, they are tellings of much less complex and interesting stories that feature many of the same plot elements as The Babadook. The Babadook - and mutatis mutandis the Turn of the Screw, 'In the Imagicon' and so forth - is a successful work precisely because it is indeterminate with respect to the existence of the titular monster and the nature of the peril which the protagonists face. Any story which lacked these features, as either of the determinate fictions we have considered must, would (all else being equal) be inferior to The Babadook in certain key respect and could not, therefore, be the same story. As an extreme example of this phenomenon, consider the 21st Century Monads song Mr Determinable. ${ }^{6}$ This song tells the story of a curious individual who possesses a number of determinable properties while failing to instantiate any determinate of those properties. We are told that he has 'an occupation', 'an animal companion' and 'a number of children' but the narrative of the song makes it clear that there is no determinate answer to the question of what kind of animal companion, or how many children, he has. Again, there is no determinate world (and a fortiori no set of worlds) where such a story could be told as known fact. Any fully determinate version of the song would simply miss the point. Or so we claim. We will have more to say about why we favour an interpretation of this kind in section 3.3 below. First, though, it is worth highlighting precisely why we take these cases to cause such problems for the standard Lewisian view.

It is a relatively simple matter to see why our account is in tension with the letter of Lewis's view. Lewis (1978: 43) explicitly rejects the claim that any individual world is itself indeterminate, claiming that

I do not know what to make of an indeterminate world, unless I regard it as a superposition of all possible ways of resolving the indeterminacy - or, in plainer language, as a set of determinate worlds that differ in the respects in question.

\footnotetext{
${ }^{6} \mathrm{~A}$ full version of the song's lyrics can be accessed here http://the21stcenturymonads.net/lyrics/MrDeterminable.html
} 
As such, while Lewis's account can easily accommodate the kind of indeterminacy present in the Holmes case, we believe that it cannot adequately model the deeper kind of indeterminacy which arises in stories such as 'In the Imagicon'. This is because, in our view, there is no determinate world (and so no set of such worlds) in which these stories are told as known fact. Given this, it would seem that such stories fall under the second part of Lewis's analysis which maintains that claims about truth in a fiction are vacuously true 'iff there are no possible worlds where [the fiction] is told as known fact' (ibid. 42). This approach is clearly problematic, though, since there are many claims concerning such works that manifestly aren't true. The governess is not able to fly under her own power, she is not haunted by pink elephants, and so forth.

It could, perhaps, be suggested that we could save a broadly Lewisian analysis by appealing (as some, such as Heintz (1979) have already suggested) not to what is true at a set of determinate worlds but, rather, to what is true at single indeterminate world. According to this suggestion, all indeterminacy can be dealt with this way. So, the world at which Macbeth is told is indeterminate with respect to the number of Lady Macbeth's children, the world of The Babadook is indeterminate concerning the existence of monsters and so on. (Of course, Lewis himself would not countenance such an appeal to indeterminate worlds as the quote above and his arguments in Lewis (1993) make clear, but we will assume that our reader is at least somewhat sympathetic to the idea of ontic indeterminacy.) We think that account has a number of advantages. Indeed, it parallels our own preferred solution in a number of respects. Our main concern, though, is that such an account would again blur the distinction between two importantly different kinds of fictional indeterminacy. On this account the worlds where Macbeth is told as known fact would contain a woman who has an indeterminate number of children just as the titular Mr Determinable does in The Monads song. Such an account would, therefore, once again leave us without the resources to explain what is interesting and amusing about the latter. Mr Determinable would be no different than the standard kinds of fictional characters who appear in Shakespearean plays, Dickens novels, Hollywood blockbusters and the like. Of course, if it transpires that there is no plausible Lewisian account which is able to respect this distinction then this would give us reason either to reject Lewis's view entirely or to explain away the apparent difference between the cases of indeterminacy we have surveyed above. We will, however, argue below that this is not the case and that a broadly Lewisian count can be constructed which is able to accommodate the important difference between these two kinds of fictional indeterminacy. 


\section{Modelling deep indeterminacy}

\subsection{Using situations}

The problem that deep indeterminacy poses for accounts of metaphysical indeterminacy can be solved by using situations, parts of possible worlds rather than whole worlds, to do the modelling. ${ }^{7}$ Situations can be most easily understood as parts of possible worlds. However, for the situation theorist this gets things the wrong way round: they will take situations as their theoretic primitive and define possible worlds as special sorts of situation. The exact nature of situations is a topic of some debate in situation theory. ${ }^{8}$ But whatever situations are, they are inherently partial: they do not tell us everything. ${ }^{9}$ For instance, the situation encompassing only World War 2 does not give us any information about World War 1, or future Martian settlers, or events happening on a distant planet in 1945. The claim of situation semantics is that it is with respect to situations that expressions or sentences are evaluated.

Evaluating with respect to situations is claimed to have a number of advantages. For just one of them, and to see the semantics at work, consider the following example from Barwise and Etchemendy (1987). ${ }^{10}$ Suppose that Emily is playing cards and has the three of clubs. ${ }^{11}$ Suppose, further, that Claire is also playing cards elsewhere in the city and also has the three of clubs. If I am watching Emily play and mistake her for Claire I might utter: 'Claire has the three of clubs'. It might seem as though what I have said isn't true. This is captured by the situation semanticist: the particular situation I'm talking about doesn't contain Claire, so doesn't include Claire having the three of clubs. In general, only the contents of the particular situation can make a statement true. It

\footnotetext{
${ }^{7}$ What follows uses the formal machinery of situation semantics. There are other semantics akin to situation semantics which might be conducive to a similar approach. In particular, Fine's Truthmaker Semantics might be a fruitful alternative way to express the metaphysical claims here advanced. What will be crucial is the partial nature of the entities under consideration and the denial of monotonicity that occurs below relating to persistence.

${ }^{8}$ Barwise (1988) lists a series of choice points for the nature of situations and their behaviour.

${ }^{9}$ One might define possible worlds as special sorts of situation that are maximal in some sense. Such situations would not be partial in that sense. There might also be an unrestrictedly maximal situation that described everything that is possible (akin to the Lewisian pluriverse): this would not be partial in any sense. Whether there are possible worlds or a maximal element are open questions in situation theory, but the point here is simply that situations do not need to be maximal in any sense. ${ }^{10}$ Kratzer (2011) describes some other areas within semantics where situations have been used productively, including anaphora and (possibly) the Liar paradox

11 The example they use is in fact not ideal; by using a definite description it adds a level of complexity. But let's take it that by saying that someone has 'the three of clubs' we simply mean that they have a card with a certain property. The example would work at least as well with 'three clubs' rather than 'the three of clubs'.
} 
matters, then, which particular situation is being picked out by a statement. This sort of contextual element is exploited by situation semanticists to capture the intuition that the statement above is not true. Situation semantics has an advantage here over possible world semantics. Possible world semantics is coarser grained because the entities it considers (worlds) are larger than situations. Possible world semantics has my utterance true as Claire does indeed have the three of clubs in the world in which I utter the statement.

This, then, can be seen as one example where situation semantics gives a distinctive interpretation. There are, of course, different formalisations of situation semantics and a number of open questions in situation theory. We shall settle only those that are necessary for the project at hand. The first to mention is that we have a choice about the truth-value of statements like 'Claire has the three of clubs' in scenarios such as the one described above. The proposition expressed is not true in a situation that doesn't contain Claire, this much is clear. But is it false? Or is it neither true nor false? We favour the latter view, as the situation seems to simply not tell us anything about Claire and her possession of the three of clubs: it is not that she is in the situation and doesn't have that card, but rather that the situation, being partial, leaves open whether she has it or not. Thus the situation semantics we are using is one according to which propositions can lack truth-values. This should not be a surprise: the partial nature of situations lends itself to a view according to which situations do not determine a truth-value for every proposition.

Two accepted parts of situation theory can now be added to the picture. They are the following:

(i) Situations can be parts of one another, and

(ii) Evaluation of the truth-value of propositions is relative to a situation.

This gives us a relation between situations and an account of truth that is situation-relative.

The parthood relations between situations together with the situation-relative truth-values of propositions invite questions about when the truth-values of propositions agree across situations related in different ways. ${ }^{12}$ Our central question is this: if some proposition $p$ is true in some

\footnotetext{
${ }^{12}$ One question is: if some proposition $\mathrm{p}$ is true in some situation $\mathrm{s}$, is $\mathrm{p}$ thereby true in all parts of $\mathrm{s}$ ? The answer is no, but this doesn't have an impact on the models we present. It should be obvious, however, that the partial nature of situations means that they don't settle the truth of everything true in their extensions.
} 
situation $\mathrm{s}$, is $\mathrm{p}$ thereby true in all situations which have $\mathrm{s}$ as a part?

Our answer is no. This issue is known as the question of persistence, and is one on which situation semanticists are divided. ${ }^{13}$ An initial reason to doubt that propositions always persist to their extensions comes from certain quantified statements. The proposition expressed by 'all the students passed the test' can be true in some small situation involving, say, only one class taking one test. But this proposition will not be true in some larger situations containing the former, for instance a situation containing all tests in a region that year. Of course, there are ways to maintain persistence, perhaps by positing implicit domain restriction in cases like the above, and replies are available to such moves too. There are other cases, though, where denial of universal persistence for 'atomic' propositions, which do not contain quantifiers, seems metaphysically productive (Pickup 2016 indicates a solution to the Ship of Theseus puzzle using similar machinery). At any rate, the denial of universal persistence is key to the model we present. So, for the sake of this solution, we will take it that propositions true in some situation are not always true in any situation that has it as a part. But, of course, propositions do often persist. Though it isn't necessary for what comes later, we think that a restricted version of persistence akin to, but not identical to, that proposed in Pickup (2016) can be endorsed:

Restricted persistence: if $\mathrm{p}$ is true in $\mathrm{s}$ and $\mathrm{s} \leq \mathrm{s} *$ then $\mathrm{p}$ is true in $\mathrm{s} *$ unless there is an $\mathrm{s}^{\prime} \leq$ $\mathrm{s} *$ such that some $\mathrm{q}$ is true in $\mathrm{s}^{\prime}$ and $\mathrm{q}$ is incompatible with $\mathrm{p}$

Now we shall show how the use of situations, along with a denial of universal persistence, can give us the right structure to express the claims of deep indeterminacy in a way that allows the cases from physics and fiction we have outlined.

\subsection{Modelling deep indeterminacy in physics}

As noted, the trouble with the BW model is that it requires complete precisifications (in the form of entire possible worlds) as the candidates between which the world is not settled. In short, as mentioned above, situations can be used as precisifications of incomplete things, and denying universal persistence will rule out problematic inferences. What it means for something to be metaphysically indeterminate is for a number of different, incompatible situations to be real

\footnotetext{
${ }^{13}$ For instance, Kratzer (1989) keeps hold of persistence, but Elbourne (2005) rejects it.
} 
candidates for the way reality is. We can maintain that these different candidate situations are all actual. But, as we shall see below, what is true in them doesn't necessarily persist to the actual world, since this would lead to contradiction and, for the quantum mechanical case, mathematical impossibility.

To spell this out for quantum mechanical metaphysical indeterminacy, consider a number of distinct situations. The first, $\mathrm{s}_{1}$, contains certain information about the properties of a quantum system. It might, for instance, have a particle spin-up in the $\mathrm{x}$ direction. Let this information be captured by a proposition $\mathrm{p}$. Thus, in $\mathrm{s}_{1}, \mathrm{p}$ is true. The second situation, $\mathrm{s}_{2}$, is one in which the quantum system has contrary properties, e.g. the particle has opposite spin in the same direction. Thus, in $\mathrm{s}_{2}$, the proposition $\sim \mathrm{p}$ is true. ${ }^{14}$ So far, nothing differs from the BW proposal. But here's the distinctive advantage of situations: not all of the properties of the quantum system need to be precise in $s_{1}$, which need for example include nothing about spin of that particle in the y-direction. Now take two further situations, $s_{3}$ and $s_{4}$. In $s_{3}$, some proposition $q$, corresponding to some value for spin in the $\mathrm{y}$-direction, is true, and $\sim \mathrm{q}$ is true in $\mathrm{s}_{4} \cdot{ }^{15} \mathrm{In}$ a scenario involving deep indeterminacy, it might be that no situation can contain determinate truth-values for both $\mathrm{p}$ and $\mathrm{q} .{ }^{16}$ But, we can hold $\mathrm{q}$ to be neither true nor false in $\mathrm{s}_{1}$ and $\mathrm{s}_{2}$. And $\sim \mathrm{q}$ will likewise lack a truth-value in $\mathrm{s}_{1}$ and $\mathrm{s}_{2}$. Similarly, both $\mathrm{p}$ and $\sim \mathrm{p}$ will fail to have a truth-value in $\mathrm{s}_{3}$ and $\mathrm{s}_{4}$. Thus in none of $\mathrm{s}_{1}-\mathrm{s}_{4}$ is there conflict with deep indeterminacy.

Let's recap. We have four situations, and, in each, one of a pair of propositions is true (and the other false) while a second pair receives no truth-value. These situations are the candidate precisifications that give rise to the indeterminacy of reality with respect to the propositions. It is unsettled which propositions are true. So far, so good. But there's a further question to ask here. What are the parthood relations that $\mathrm{s}_{1}-\mathrm{s}_{4}$ stand in? Obviously none of them are parts of one another. But we can construct larger situations out of them (in standard situation theory situations obey unrestricted and unique fusion). Consider, in particular, whether the situation $\mathrm{S}$ that is the whole world contains as parts all of $s_{1}-s_{4}$. On the version of the situation-theoretic approach we are outlining here, $\mathrm{S}$ does indeed have all of $\mathrm{s}_{1}-\mathrm{s}_{4}$ as parts: the world contains all of its candidate

\footnotetext{
${ }^{14}$ Depending on the exact semantics, this may be equivalent to the falsity of $\mathrm{p}$.

15 There would also be further situations in which other propositions are true, in the quantum mechanical case, but two pairs suffice for the demonstration.

${ }^{16}$ The Kochen-Specker theorem strictly applies only to more complex structures of observables, but the conceptual point is the same (recall that we only take the quantum-mechanical case as a motivating example).
} 
precisifications. But doesn't this mean that the world itself is contradictory, as it contains parts that determinately disagree about the truth of some propositions? Now we see the benefit of the denial of universal persistence. For if we accepted universal persistence, we would be required to hold that anything true in a part of S is thereby true in S. Thus $\mathrm{p}$ and q would both get determinate truthvalues, in violation of deep indeterminacy, and furthermore $p$ and $\sim p$ would both be true, in violation of non-contradiction. Instead, we maintain that these propositions, though true in parts of $\mathrm{S}$, are not true in S. They fail to persist from the sub-situations to the larger situation: they lose truth-value. The restricted persistence condition above gives this result. In this way, the world can contain parts that fundamentally disagree but not be contradictory.

To spell out the view: we propose to replace the original BW structure with a new structure. BW evaluated propositions with respect to sets of ersatz possible worlds. These possible worlds are the candidate precisifications of reality. For BW, it is indeterminate whether $\mathrm{p}$ if some of the ersatz worlds that are candidates for representing actuality are p-worlds, and some are $\sim p$-worlds. To be a candidate for representing actuality is to not determinately fail to represent actuality.

Our structure evaluates propositions with respect to sets of (sharply defined but typically local and incomplete) situations. These situations are the candidate precisifications of parts of reality, and are all parts of the maximal actual-world situation S. It is indeterminate whether $\mathrm{p}$ if some of the situations that are parts of S are situations in which $\mathrm{p}$ is true and some of the situations that are parts of $\mathrm{S}$ are situations in which $\mathrm{p}$ is false. Truths in parts of situations persist to whole situations unless they conflict with truths in another part of the whole situation. If they do conflict, they are indeterminate in the whole situation.

\subsection{Modelling deep indeterminacy in fiction}

In this section we present our own modified Lewisian account of fictional indeterminacy. Before doing so, though, it is worth noting that the kind of indeterminacy we are concerned with - as with the kind of deep physical indeterminacy we discussed above - cannot be modelled using a standard version of the BW account. Recall that each of the possible worlds they postulate ascribes fully determinate truth-values to every proposition. The source of metaphysical indeterminacy lies not in the worlds themselves but, rather, in its being indeterminate which of them is actual. As such there will still be no world where a story like The Babadook is told as known fact. Instead there

will only be worlds where, for example, some less interesting monster story is told. Given this, the 
Lewisian who adopts the BW account of indeterminacy will face precisely the same problem encountered by Lewis's original view. ${ }^{17}$ On our account, by contrast, there will be possible situations in which stories of this kind, and not merely determinate parts or variations of them, are told as known fact. A narrator in one of these situations can truly tell a story that is indeterminate between the different interpretations of The Babadook because the situation they inhabit is itself indeterminate in these respects.

To see how this might come about, start by considering two possible situations. In one of these $\left(\mathrm{B}_{1}\right)$ a close cousin of The Babadook story which features a real monster is told as known fact and in the other $\left(\mathrm{B}_{2}\right)$ a story where there is no monster is told as known fact. Now, consider a third situation $\left(\mathrm{B}_{3}\right)$ which combines the two. It is in $\mathrm{B}_{3}$, we maintain, that someone will be able to tell The Babadook itself as known fact. While it will be determinate with respect to $\mathrm{B}_{1}$ that there is a monster and determinate with respect to $\mathrm{B}_{2}$ that there is not, there will be no determinate fact of the matter regarding the monster's existence in $\mathrm{B}_{3}$. Recall that, on our model, all of those things which are true in $\mathrm{B}_{1}$ (and likewise $\mathrm{B}_{2}$ ) will be true in $\mathrm{B}_{3}$ unless they conflict with what is true in some other situation which is also part of $\mathrm{B}_{3}$. So it will be straightforwardly true in $\mathrm{B}_{3}$ that Amelia has a son called Samuel, that they live in Australia, and so forth. Conversely, it will be straightforwardly false that they reside in Peru and that they lead happy carefree lives. However, it will not be determinately true in $\mathrm{B}_{3}$ that there is a monster (since this conflicts with what is the case in $\mathrm{B}_{2}$ ) nor that there isn't (since this conflicts with what is the case in $\left.B_{1}\right) \cdot{ }^{18}$ Rather, the truth-value of the claim 'there is a monster' will be indeterminate.

What is true in The Babadook will, therefore, be what is true in each of the situations such as $\mathrm{B}_{3}$ where the story itself is told as known fact. There will, however, be two ways for a proposition to be indeterminate with respect to such a fiction. The first (shallow fictional indeterminacy) arises when a claim is true in some Babadook worlds and false at others. The second (deep fictional indeterminacy) occurs when the truth value of a proposition is itself indeterminate in each of the Babadook worlds. In the Holmes stories, by contrast, we only have indeterminacy of the first (shallower) kind. Thus we have a clear Lewisian explanation for the important, and neglected, difference between these different kinds of fictional determinacy.

\footnotetext{
17 There is also the difficulty of combining something like the BW account with a genuine, rather than ersatz, form of modal realism. We will not, however, pursue such concerns here.

18 Though it will be determinately true that there either is or isn't a monster since this disjunction is true in both $\mathrm{B}_{1}$ and $\mathrm{B}_{2}$.
} 


\section{Conclusion}

We have explored two areas that motivate theorizing about indeterminacy - in fiction and in physics. Moreover, when we consider in more detail the kinds of indeterminacy involved, they both appear to feature something that one might initially not suspect: deep indeterminacy. This is significant because the natural ways of thinking about indeterminacy in both domains appear to be unable to handle deep indeterminacy. At this point, in other cases involving friction between philosophy and other domains of enquiry, various moves are familiar in the philosophical literature, and all might be made here:

For example, a conservatively inclined philosopher might dig in and declare the phenomenon in question impossible. In the case of deep metaphysical indeterminacy they might see the impossibility of deep indeterminacy - or of metaphysical indeterminacy at all - as a constraint on the proper interpretation of quantum mechanics. If, say, a version of GRW on offer involves indeterminacy in the world, then reject that version of GRW. In the case of deep fictional indeterminacy, the conservative line would be to declare that an author, no matter what their intention, simply cannot produce a fiction that is indeterminate in the relevant sense. They can make one that is incomplete, or one in which a fictional narrator thinks that there is indeterminacy, but not one that is genuinely indeterminate (see Hanley (2004: 120) for parallel moves concerning certain kinds of impossible fiction).

Alternatively, a 'naturalistically' inclined metaphysician would see the constraint the other way round: conservatism is insufficiently deferential to the source of the phenomena. In the case of the BW model, perhaps the philosophers' fetish for nice complete possible worlds is at fault. In the fiction case, again it is the Lewisian orthodoxy and the machinery of worlds that is seen to be inadequate to the task.

In adapting the models of indeterminacy in question, we have accepted something like the latter challenge: rather than dig in, the metaphysician ought to adapt. But unlike the more adventurous naturalistic metaphysician, we prefer to emphasise the naturalness with which orthodox analytic metaphysics provides the answers - the move to situations is nothing like the wholesale rejection of this kind of framework advocated by its detractors such as Ladyman and Ross (2007). On the contrary, mainstream analytic metaphysics is a much richer source of tools, as is reflected in the "Viking" approach of French and McKenzie (2012). And in the context of the present volume, the 
important point is this: the richness of those tools only becomes apparent when one considers the full range of their application: problems drawn from areas as apparently disparate as the philosophy of art and philosophy of science motivate common solutions and provide mutual insight.

\section{References}

Barnes, Elizabeth, and Ross Cameron. "The open future: bivalence, determinism and ontology." Philosophical Studies 146, no. 2 (2009): 291-309.

Barnes, Elizabeth, and Robbie Williams. "A Theory of Metaphysical Indeterminacy". Oxford Studies in Metaphysics 6 (2011):103-148

Bernstein, Sara. "Causal and Moral Indeterminacy." Ratio (forthcoming).

A Bokulich. Metaphysical Indeterminacy, Properties, and Quantum Theory. Res Philosophica, 91

(3):449-475, 2014.

Currie, Gregory. The nature of fiction. Cambridge University Press, 1990.

DíAlessandro, William. "Explicitism about Truth in Fiction." The British Journal of Aesthetics (forthcoming).

French, Steven and Kerry McKenzie 2012. 'Thinking Outside the Toolbox: Toward a more Productive Engagement between Metaphysics and Philosophy of Physics', European Journal of Analytic Philosophy 8 (1):42-59 (2012)

Friend, Stacie. "The great beetle debate: a study in imagining with names." Philosophical Studies 153, no. 2 (2011): 183-211.

Hanley, Richard. "As good as it gets: Lewis on truth in fiction." Australasian Journal of Philosophy 82, no. 1 (2004): 112-128.

Heintz, John. "Reference and inference in fiction." Poetics 8, no. 1-2 (1979): 85-99.

Irvin, Sherri. "Authors, intentions and literary meaning." Philosophy Compass 1, no. 2 (2006): 114128.

Keefe, Rosanna. "Vagueness: supervaluationism." Philosophy Compass 3, no. 2 (2008): 315-324. 
Kenton, Edna. "Henry James to the Ruminant Reader: The Turn of the Screw." In The Arts, vol. 6, pp. 245-55. 1924.

Knights, Lionel Charles. How many children had Lady Macbeth?: An essay in the theory and practice of Shakespeare criticism. G. Fraser, The Minority Press, 1933.

Ladyman, James and Don Ross, Every Thing Must Go, OUP 2007

Lewis, David. "Truth in fiction." American Philosophical Quarterly 15, no. 1 (1978): 37-46.

--. "Postscript to truth in fiction." In Philosophical Papers Volume One. Oxford University Press 276-280 (1983).

--. "Many, but Almost One" in John Bacon, ed. Ontology, Causality, and Mind: Essays in Honour of DM Armstrong. Cambridge : Cambridge University Press (1993): 23-42.

Margolis, Joseph. "Robust relativism." The Journal of Aesthetics and Art Criticism 35, no. 1 (1976): $37-46$.

Matravers, Derek. "Truth in Fiction: A Reply to New." The Journal of Aesthetics and Art Criticism 55, no. 4 (1997): 423-425.

New, Christopher. "A note on truth in fiction." The Journal of Aesthetics and Art Criticism 55, no. 4 (1997): 421-423.

M Pickup. “A Situationalist Solution to the Ship of Theseus Puzzle.” Erkenntnis 81(5) (2016): 973992.

Priest, Graham. "Sylvan's Box: A Short Story and Ten Morals." Notre Dame Journal of Formal Logic 38, no. 4 (1997): 573-582.

Sorensen, Roy A. "Fictional incompleteness as vagueness." Erkenntnis 34, no. 1 (1991): 55-72.

Stecker, Robert. "Art interpretation." The Journal of aesthetics and art criticism 52, no. 2 (1994): 193-206.

--. "Relativism about interpretation." The Journal of Aesthetics and Art Criticism 53, no. 1 (1995): $14-18$.

--. Vagueness and contradiction. Oxford: Clarendon Press, 2001.

Williams, J. Robert G. "Nonclassical Minds and Indeterminate Survival." Philosophical Review 1 J R G Williams. Ontic Vagueness and Metaphysical Indeterminacy. Philosophy Compass, pages $1-30,2008$

Williamson, Timothy. Vagueness. New York: Routledge, 2002.23, no. 4 (2014): 379-428.

J Wilson. A Determinable-Based Account of Metaphysical Indeterminacy. Inquiry, 56(4):359-385, 2013

Woodward, Richard. "Truth in fiction." Philosophy Compass 6, no. 3 (2011): 158-167. 